\title{
Evaluation of Eta Weather Forecast Model over Central Africa
}

\author{
Romeo Steve Tanessong*, Derbetini A. Vondou, P. Moudi Igri, F. Mkankam Kamga \\ Laboratory for Environmental Modelling and Atmospheric Physics, Department of Physics, University of Yaounde 1, Yaounde, \\ Cameroon \\ Email: "tanessrs@yahoo.fr
}

Received April 1, 2012; revised May 3, 2012; accepted May 14, 2012

\begin{abstract}
The main goal of this work is to investigate the skills of Eta weather forecast model in forecasting precipitations, temperature and sea level pressure. The model domain extends from $6^{\circ} \mathrm{W}$ to $29^{\circ} \mathrm{E}$ and $6^{\circ} \mathrm{S}$ to $21^{\circ} \mathrm{N}$. The model is run with a horizontal resolution of $48 \mathrm{~km}$ with 45 vertical levels and initial and boundary conditions were given by National Centers for Environmental Prediction (NCEP) 00UTC operational analysis. All the forecasts are for period of 48 hours. They were compared to the Tropical Rainfall Measuring Mission (TRMM) derived data for precipitations and NCEP/ NCAR (National Center for Atmospheric Research) analysis for temperature and sea level pressure. The results show that Eta model predicts fairly good 2 meters temperature and the sea level pressure. Spatial distributions of precipitations are not well simulated by the model.
\end{abstract}

Keywords: Precipitations; Temperature; Sea Level Pressure; Eta Model

\section{Introduction}

Even since, many aspects of human's lives were influenced by the weather. Throughout the history, civilizations suffered from its direct impact on many sectors such as transport agriculture [1], health, etc. Severe weather events such as tornadoes, hurricanes, storms, droughts, floods are recurring nowadays more frequently than in the past, threatening people's lives and unfortunately, leading to the loss of thousands of them. Furthermore, costs from the natural disasters caused by the weather are enormous. The Numerical Weather Prediction (NWP) was developed as one tool to try to predict the evolution of time and especially extreme events.

Nowadays, several NWP models were developed and continue to grow due to the increase of computing power available and improved knowledge of the workings of the atmosphere [2]. NWP models are in the form of global models (GCMs) or regional models (RMs). GCMs that represent in detail the atmospheric dynamics and physical processes that take place, have shown great effectiveness in representing large-scale phenomena. However, GCMs are limited when it involves taking into account the microscale and mesoscale features [2]. The RMs are used to try to improve some aspects of GCMs. They generally run using a sufficiently fine mesh screen and can better represent the conditions of the boundary layer such as topography, vegetation, soils and coasts.

${ }^{*}$ Corresponding author.
The RMs may also better represent mesoscale phenomena and micro-scales. It should be noted that these improvements are limited by the quality of lateral boundary conditions. The NWP generally require a very large computational cost [3].

There are several processes in the atmosphere that can not be directly described by the equations that describe the atmospheric circulation such as vertical convection, cloud physics, atmospheric radiative effects, turbulence, condensation, evaporation, etc. The method used to include the effects of physical processes in the model is called parameterization. The convection schemes commonly used are: Kain-Fritsch scheme [4], Betts-MillerJanjic scheme [5].

In this work, Eta model is used because of its better representation of the topography [6]. The Eta Model was also chosen because there are few investigations using the Eta Model over Central Africa and because the vertical coordinate system used in this model is recommended for use over Central Africa due to the presence of steep topography.

Eta model has been used in studies of seasonal forecasts over South America [7] where the forecasts were improved with respect to the driver global model. Fennessy and Shukla [8] showed that the Eta model provides forecasts of average (daily and seasonal) rainfall close enough observations in Northern and Northeastern Brazil. They showed however that precipitations are not well simulated by the model. 
The purpose of this study is to evaluate the skills of Eta NWP model over Central Africa in predicting precipitation, 2 meters temperature and the sea level pressure.

Simulations of precipitation are compared to the Tropical Rainfall Measuring Mission (TRMM) derived data for precipitations and the two other parameters are compared to the NCEP/NCAR analysis data.

In the next section, model, data and Methodology will be described. Section 3 will present the results and discussions. Finally, Section 4 is devoted to conclusion.

\section{Model, Data and Methodology}

The Eta Model [9] was developed at Belgrade University and was operationally implemented by the National Centers for Environmental Prediction [6]. The Eta is a hydrostatic Model, which uses the $\eta$ vertical coordinate defined by Mesinger [10] as

$$
\eta=\frac{p-p_{t}}{p_{s}-p_{t}} \frac{p_{r f}(z s)-p_{t}}{p_{r f}(0)-p_{t}}
$$

here $p$ is the pressure; the subscripts $\mathrm{t}$ and stand for the top and the surface values; $z$ is the geometric height, and $p_{r f}(\mathrm{z})$ is a reference pressure as a function of $z$. The $\eta$ coordinate improves the calculation of horizontal derivatives near steep topographic areas. Because the surfaces of the coordinate are approximately horizontal, this feature is particularly useful for regions with steep orography such as Central Africa.

The prognostic variables are temperature, specific humidity, horizontal wind, surface pressure, the turbulent kinetic energy and cloud liquid water/ice. These variables are distributed on the Arakawa type E-grid.

The treatment of turbulence is based on the MellorYamada level 2.5 procedure [11]; the radiation package was developed by the Geophysical Fluid Dynamics Laboratory, with long wave and solar radiation parameterized according to Fels and Schawarztkopf [12] and Lacis and Hansen [13], respectively.

The study area ranges from $6^{\circ} \mathrm{W}$ to $29^{\circ} \mathrm{E}$ longitude and $6^{\circ} \mathrm{S}$ to $21^{\circ} \mathrm{N}$ latitude. The model is initialized at $00 \mathrm{UTC}$ by the NCEP Global Forecasting System (GFS), which also provides the boundary conditions of the Eta model every 6 hours and is performed for the period ranging for october to December 2006. Simulations are run for 48 hours at a spatial resolution of $48 \mathrm{~km}$ with 45 vertical levels. The model is established with the top of the model at $25 \mathrm{hPa}$. The convection scheme of Kain-Fritsh [4] and Betts-Miller-Janjic scheme [5] are used. Briefly, the Betts-Miller-Janjic scheme (BMJ) is an adjustment-type scheme that forces soundings at each point toward a reference profile of temperature and specific humidity. The scheme's structure favors activation in cases with sub- stantial amounts of moisture in low and midlevels and positive convective available potential energy (CAPE). The Kain-Fritsh (KF) scheme removes CAPE (calculated using the traditional, undiluted parcel-ascent method) through vertical reorganization of mass. The scheme consists of a convective trigger function (based on gridresolved vertical velocity), a mass flux formulation, and closure assumptions. The BMJ and KF schemes are known to differ in some features of their predicted rainfall, and in the response to atmospheric background conditions. Gallus and Segal [14], for instance, found large differences in the BMJ and KF bias scores. In addition, the above convective schemes have been used widely [13], thus furthermore providing merit to their adoption in the present study.

For the purpose of verification, we used the Tropical Rainfall Measuring Mission (TRMM) data as ground thruth. In Central Africa, there is very few weather stations. TRMM is a mission Joint American National Aeronautics and Space Administration (NASA) and the Japanese National Space Development Agency (NASDA) to measure precipitation in the tropics and subtropics. In this work, version 6 of the 3B42 combined is used. Version 6 of the 3B42 product provides three hourly estimations of rainfall on a grid of $0.25^{\circ} \times 0.25^{\circ}$. Nicholson et al. [15] evaluated TRMM products over West Africa over the period May to September. They found that TRMMmerged rainfall products showed excellent agreement with gauge data over West Africa on monthly-to-seasonal timescales and $0.25^{\circ} \times 0.25^{\circ}$ latitude/longitude spatial scales. We also used NCEP/NCAR data. The NCEP/ NCAR data used in this work are values of every six hours of the analysis data for October, November and December 2006. The horizontal grid measures $2.5^{\circ}$ side.

To validate the model, we proceeded as follows:

For precipitation: We calculated the 6,12 and 24 hours accumulated precipitation for both convective schemes that we combined with the bias and correlation coefficient. The bias is the average gap between the fields, it is defined as:

$$
\operatorname{Bias}=\frac{1}{n_{e}} \sum_{i=1}^{n_{e}}\left(x_{i}-y_{i}\right)=\bar{x}-\bar{y}
$$

where $n e$ is the number of grid points, $x_{i}$ is the value of the variable to the $i$ th grid point of Eta, $y_{i}$ is the value of the variable to the $i$ th grid point of observation.

The correlation coefficient between two fields is defined as:

$$
r=\frac{\sum_{i=1}^{n_{e}}\left(x_{i}-\bar{x}\right)\left(y_{i}-\bar{y}\right)}{\sqrt{\sum_{i=1}^{n_{e}}\left(x_{i}-\bar{x}\right)^{2} \sum_{i=1}^{n_{e}}\left(y_{i}-\bar{y}\right)^{2}}}
$$

$\bar{x}$ is the time average of Eta field;

$\bar{y}$ is the time average of observation field. 
For temperature and sea level pressure, we plotted graphs every 3 hours and we compared with the analysis data. For a good comparison, we took the departures between these projections and observations. As for precipitation, we calculated the bias and correlation coefficient. These quantities are defined as above.

\section{Results and Discussions}

\subsection{Meters Temperature, Reduced Mean Sea Pressure}

The Bias and correlation coefficient of some days (the other days present the same tendency) are presented in Table 1. The Bias and correlation coefficient were evaluated based on the daily error, corresponding to the first 24 hours of each 48-hours integration. It was observed that the Eta model presented smaller bias and greater correlation coefficient during the study period. The higher resolution and a better representation of topography used in Eta model seem to contribute substantially to an improvement of the 2 meters temperature.

Figures $\mathbf{1}$ and $\mathbf{2}$ display the temperature obtained from Eta model simulation, analyses data and difference between the two fields at $00 \mathrm{~h}$ and $06 \mathrm{~h}$. Figures obtained from the analysis data are consistent with the decrease of temperature in a north-south direction.

The largest differences are observed in western Cameroon, part of the Adamawa Plateau and northern Sudan. These differences were less than $-6^{\circ} \mathrm{C}$. The differences between the Eta model simulations and analysis data could be due to errors in model parameterization. Indeed, the choice and adjustment of parameterization schemes has a significant impact on the quality of the forecast [16]. In the case of Western Cameroon, characterized by complex terrain [17], errors due to topography are also noted. Indeed, we used as input data GFS (Global Forecasting System). The GFS is a global model using the Sigma coordinate as vertical coordinate. The main draw backs of this coordinate lies on the calculation of the pressure gradient force in the mountainous areas thus affecting the quality of prediction in these regions.

Table 1. Values of bias and correlation coefficient $(r)$.

\begin{tabular}{cccc}
\hline Day & Variable & Temperature $\left({ }^{\circ} \mathrm{C}\right)$ & Pressure $(\mathrm{hPa})$ \\
\hline 23 October & Bias & -1.67 & -1.18 \\
2006 & $r$ & 0.93 & 0.92 \\
& Bias & -1.12 & -1.78 \\
20ctober & $r$ & 0.94 & 0.94 \\
30 October & Bias & -1.48 & -1.25 \\
2006 & $r$ & 0.92 & 0.95 \\
31 October & Bias & -1.37 & -1.40 \\
2006 & $r$ & 0.91 & 0.96 \\
\hline
\end{tabular}
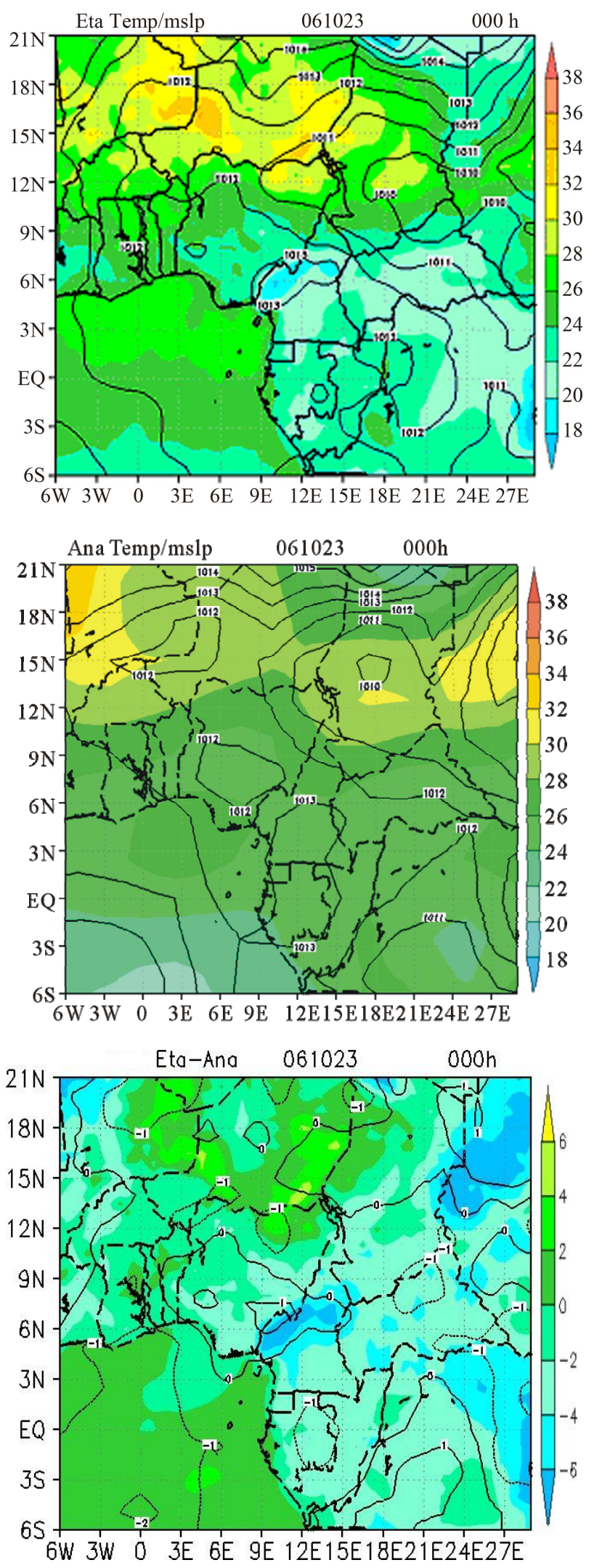

Figure 1. Temperature and sea level pressure (contours): Eta (top), analysis data (middle) and difference (bottom) at 00 h 23-10-2006. 

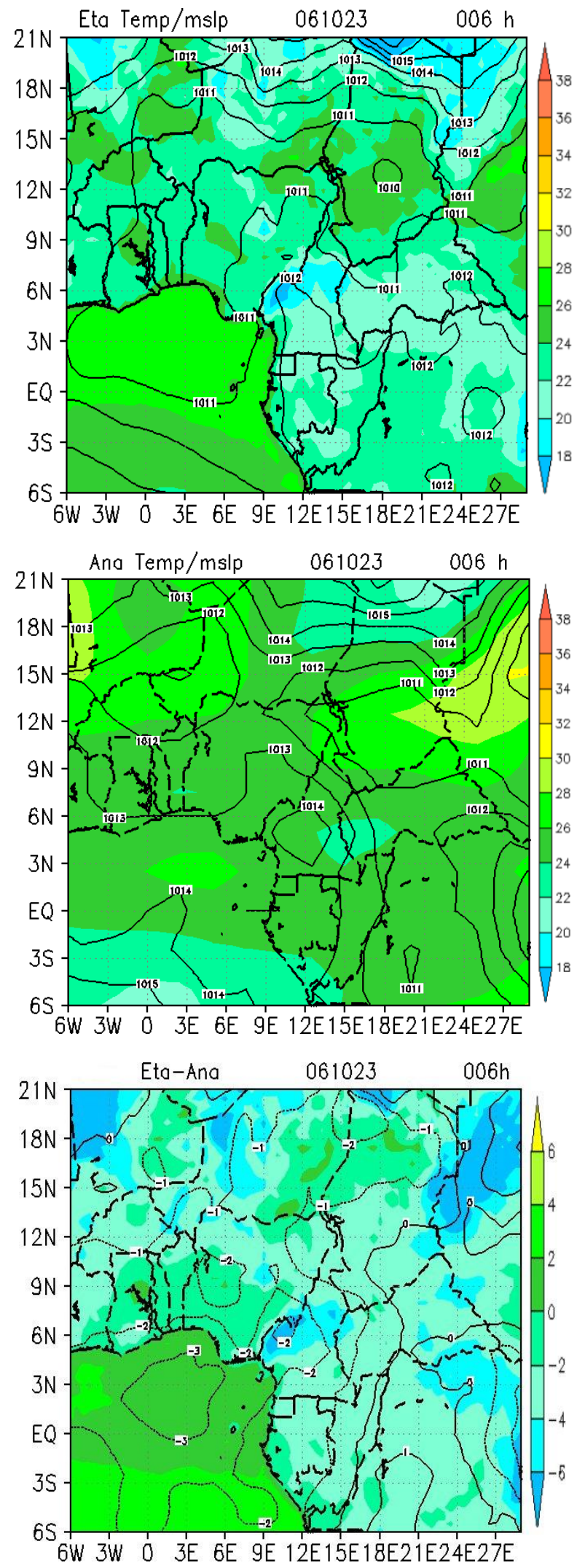

Figure 2. Temperature and sea level pressure (contour lines): Eta (top), Analysis data (middle) and difference (bottom) at $06 \mathrm{~h} \mathrm{23-10-2006.}$
The unavoidable source of error in NWP models comes from initial data. Even a perfect model (i.e. perfect parameterization, mesh sufficiently fine, no errors due to numerical methods adopted) could not produce a perfect forecast, as errors in initial conditions will then grew louder in the forecast and it will diverge from reality. The determination of the atmospheric state at the beginning of the forecast is itself a major scientific challenge.

\subsection{Precipitations}

Figure 3 presents 6 hours accumulated rainfall. KF, BMJ schemes and TRMM show zero precipitation fields in the north of $12^{\circ} \mathrm{N}$. Precipitations simulated by the KF and BMJ schemes are oriented along east-west direction. The maximum simulated by the KF scheme is $20 \mathrm{~mm}$ and is located toward the center of Ghana; the BMJ scheme maximum is $40 \mathrm{~mm}$ and is located in the same region. TRMM maximum is $80 \mathrm{~mm}$ around $6^{\circ} \mathrm{S}-18^{\circ} \mathrm{E}$. Neither of the two schemes was detected this maximum. KF and BMJ schemes have very dense precipitation fields compared to TRMM. In general, there's an important difference between KF, BMJ scheme and TRMM. The 24hour accumulated precipitation simulated by the Eta model (figures not shown) exhibit maxima of the same order of magnitude as the observations. It should be noted that 6 -hour accumulated precipitation, is more difficult to forecast than the 24-hour accumulated precipitation.

Precipitation results from several processes, which makes modeling difficult. For Eta like most numerical weather models, rainfall is separated into two groups: convective precipitation (mainly related to an upward vertical motion of air mass and its condensation by adiabatic expansion) and stratiform precipitation (related to horizontal movement of air particles and their saturation when moisture convergence is sufficient). Exceptionally heavy events may be associated with organized mesoscale convective systems (MCSs) embedded in large scale synoptic systems, but the majority of rainfall episodes are linked to isolated convective cells not excessing a few hundred meters in extension.

After this analysis, we can note first of all a sizeable gap on the accumulated rainfall; neither convective schemes used is well suited to simulate rainfall. The spatial distribution of precipitation is errenous.

\section{Conclusions}

The 2-meter temperature and the sea level pressure have been compared to NCEP/NCAR analysis data. The 6,12 and 24 hours accumulated rainfall were also compared to the Tropical Rainfall Measuring Mission (TRMM). The results show that temperature and the sea level pressure are quite well simulated by the Eta model. The strong 

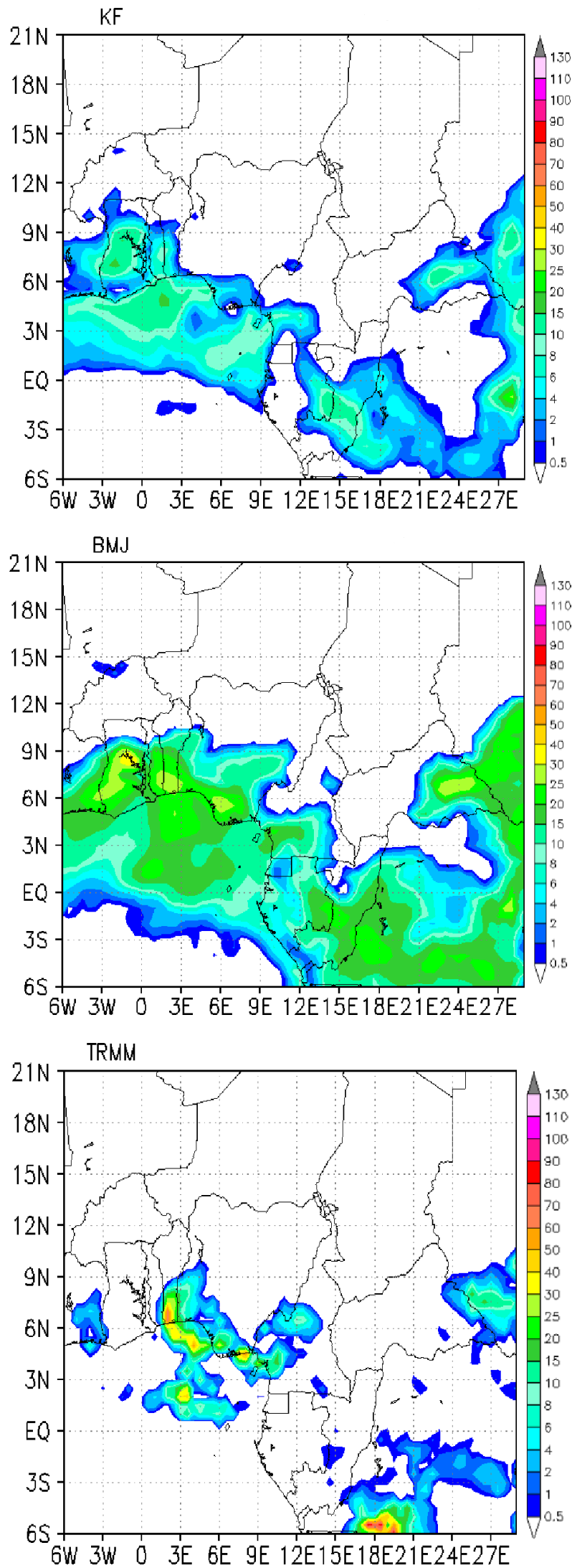

Figure 3. 6 hours accumulated precipitation: $00 \mathrm{~h}-06 \mathrm{~h}$ of 23-10-2006. correlation coefficients (Table 1) justify this assertion. The precipitations are not well simulated by the model. There is a poor spatial distribution of precipitation around the equator. The discordances observed may be due to errors of parameterization in the model. Indeed, the choice and adjustment of parameterization schemes has a significant impact on the quality of prediction [16]. These errors may also come from initial data. Even a perfect model (i.e. perfect parameterization, mesh sufficiently fine, no errors due to numerical methods adopted) could not produce a perfect forecast for errors in initial conditions will then grew louder in the forecast and that it diverge from reality.

In our future work, we intend to change the model parameterization (e.g. frequency of advection). If the forecasts are improved, we will do simulations with higher resolution. This will allow us to better appreciate the performance of the Eta NWP model to simulate rainfall locally. We also aim to perform those simulations with Weather Research and Forecasting Model (WRF) using probabilistic forecasts and data assimilation.

\section{Acknowledgements}

We thank the Maroochy Shire project working group, led by Damian McGarry, who provided the wide range of data and analysis for the analysis. We also thank Dr. Heinz Schandl of CSIRO for suggestions to improve the paper.

\section{REFERENCES}

[1] K. F. Mkankam and B. C. Mbane, "Analysis of Daily Precipitation Time Series of the Cameroon Meteorological Network," Science \& Technology Development, Vol. 7, 2000, pp. 77-83.

[2] E. Rogers, D. G. Deaven and G. J. Dimego, "The Regional Analysis System for the Operational Eta Model: Original 80-km Confguration and Recent Changes," Weather and Forecasting, Vol. 10, No. 4, 1995, pp. 810825.

doi:10.1175/1520-0434(1995)010<0810:TRASFT $>2.0 . C$ $\underline{\mathrm{O} ; 2}$

[3] T. M. Hamill and S. J. Colucci, "Verification of EtaRSM Short-Range Ensemble Forecasts," Monthly Weather Review, Vol. 125, No. 6, 1997, pp. 1312-1327. doi:10.1175/1520-0493(1997)125<1312:VOERSR > 2.0.C $\underline{\mathrm{O} ; 2}$

[4] J. S. Kain and J. M. Fritsch, "Convective Parameterization for Mesoscale Model: The Kain-Fritsch Scheme. The Representation of Cumulus Convection in Numerical Models," Meteorological Monographs, Vol. 46, 1993, pp. 165-170.

[5] Z. I. Janjic, "The Step-Mountain Eta Coordinate Model: Further Developments of the Convection, Viscous Sublayer, and Turbulence Closure Schemes," Monthly Weather Review, Vol. 122, No. 5, 1994, pp. 927-945. 


\section{doi:10.1175/1520-0493(1994)122<0927:TSMECM $>2.0$.} $\underline{\mathrm{CO} ; 2}$

[6] T. Black, "The NMC Mesoscale Eta Model: Description and Forecast Examples," Weather and Forecasting, Vol. 9, No. 2, 1994, pp. 265-278. doi:10.1175/1520-0434(1994)009<0265:TNNMEM>2.0. $\underline{\mathrm{CO} ; 2}$

[7] S. C. Chou, J. F. B. Fonseca and J. L. Gomes, "Evaluation of Eta Model Seasonal Precipitation Forecasts over South America," Nonlinear Processes in Geophysics, Vol. 12, No. 4, 2005, pp. 537-555. doi:10.5194/npg-12-537-2005

[8] M. J. Fennessy and J. Shukla, "Seasonal Prediction over North America with a Regional Model Nested in a Global Model," Journal of Climate, Vol. 13, No. 14, 2000, pp. 2605-2627. doi:10.1175/1520-0442(2000)013<2605:SPONAW $>2.0$. $\mathrm{CO} ; 2$

[9] F. Mesinger, Z. I. Janjic, S. Nickovic, D. Gavrilov and D. G. Deaven, "The Step-Mountain Coordinate: Model Description and Performance for Cases of Alpine Lee Cyclogenesis and for a Case of an Appalachian Redevelopment," Monthly Weather Review, Vol. 116, No. 7, 1988, pp. $1493-1518$. doi:10.1175/1520-0493(1988)116<1493:TSMCMD $>2.0$. $\mathrm{CO} ; 2$

[10] F. Mesinger, “A Blocking Technique for Representation of Mountains in Atmospheric Models," Avition Meteorological Aeronautics, Vol. 44, 1984, pp. 195-202.

[11] G. L. Mellor and T. Yamada, "Development of a Turbulence Closure Model for Geophysical Fluid Problems," Reviews of Geophysics and Space Physics, Vol. 20, No. 4,
1974, pp. 851-875. doi:10.1029/RG020i004p00851

[12] S. B. Fels and M. D. Schawarztkopf, "The Simplified Exchange Approximation: A New Method for Radiative Transfer Calculations," Journal of the Atmospheric Sciences, Vol. 32, No. 7, 1975, pp. 1475-1488. doi:10.1175/1520-0469(1975)032<1475:TSEAAN $>2.0 . C$ $\underline{\mathrm{O} ; 2}$

[13] A. A. Lacis and J. E. Hansen, "A Parametrization of the Absorption Dissipation in the Atmosphere from LargeScale Balance Requirements," Monthly Weather Review, Vol. 49, 1975, pp. 608-627.

[14] W. A. J. Gallus and M. Segal, "Does Increased Predicted Warm Season Rainfall Indicate Enhanced Likelihood of Rain Occurrence?" Weather and Forecasting, Vol. 19, No. 6, 2004, pp. 1127-1135. doi:10.1175/820.1

[15] S. E. Nicholson, B. Some, J. McCollum, E. Nelkin, D. Klotter, Y. Berte, B. M. Diallo, I. Gaye, G. Kpabeba, O. Ndiaye, J. N. Noukpozounkou, M. M. Tanu, A. Thiam, A. A. Toure and A. K. Traore, "Validation of TRMM and Other Rainfall Estimates with a High-Density Gauge Dataset for West Africa. Part II: Validation of TRMM Rainfall Products," Journal of Applied Meteorology, Vol. 42, No. 10, 2003, pp. 1355-1368.

[16] J. Venkata Ratnam and J. Krishna Kumar, "Sensitivity of the Simulated Monsoons of 1987 and 1988 to Convective Parameterization Schemes in MM5," Journal of Climate, Vol. 18, 2005, pp. 2724-2741.

[17] E. Richard, A. Buzzi and G. Zangl, "Quantitative Precipitation Forecasting in the Alps: The Advances Achieved by the Mesoscale Alpine Programme," Quarterly Journal of the Royal Meteorological Society, Vol. 133, 2007, pp. 831-846. 